\title{
USING OF ELECTRON MICROSCOPY FOR TOOL WEAR EVALUATION
}

\author{
Natasa Naprstkova ${ }^{1}$, Jaromír Cais ${ }^{1}$, Pavel Kraus ${ }^{1}$, Miroslava Tavodova ${ }^{2}$ \\ ${ }^{1}$ J. E. Purkyně University in Ústí nad Labem, Czech Republic; \\ ${ }^{2}$ Technical University of Zvolen, Slovak Republic \\ naprstkova@fvtm.ujep.cz, miroslava.tavodova@tuzvo.sk
}

\begin{abstract}
Using of cutting inserts is currently a normal part of the manufacturing process. The article deals with the tool wear evaluation of selected inserts for turning by electron microscopy. Use of electron microscopy helps closer analysis of machining consequences for these plates, because the microscope images captured with the electron microscope have a greater depth of sharpness and can display the examined object with greater plasticity. It is another way to explore objects and extends the possibilities for obtaining large quantities of information. Electron microscopy is possible to be used for getting better information about toolwear after machining, for example, too. One of the possible usages during the research is in the area of toollife of cutting inserts, which is realized at the Faculty of Production Technology and Management of Jan Evangelista Purkyně University in Ústí nad Labem. As part of this research various analyzes were also carried out. Part of such research was to analyze the resulting tool wear of the used inserts after turning of selected material also by electron microscopy, specifically the SEM analysis. The SEM analysis can show more and more what in the surveyed area might happen in comparison with conventional microscopy. Images are sharper and more stereoscopic and some aspects are more noticeable. That is why SEM was used as a complementary analysis method throughout this research. As an experimental material hardened steel class 16343 according to the CSN 410002 has been used. The experimental material was turned on the three-axis CNC lathe DOOSAN Lynx 220L with the control system FANUC.
\end{abstract}

Keywords: tool wear, electron microscopy, tool life.

\section{Introduction}

At the Faculty of Production Technology and Management, which is part of the Jan Evangelista Purkyně University in Ústí nad Labem several research projects are carried out. One of them is research in the area of tool life of cutting inserts, because using of cutting inserts is currently a common part of the manufacturing process and it is very interesting for production companies. As part of this research various analyzes were also carried out. One of these was analysis of tool life of experimental inserts by the SEM analysis, which is available at FPTM JEPU [1-3].

The SEM analysis was used to supplement the final examination of the insert tool wear after machining.

The abbreviation SEM means a scanning electron microscope. This microscope is working with a narrow electron beam. To formation of images primary and secondary electrons are used backscattered from the sample surface. These electrons are formed by the interaction of atoms of the sample with electrons of the electron beam. The detector receives and processes the electrons so as to obtain a sharp image of the sample surface. Rather than a traditional optical microscope its advantage is a large depth of focus and the ability to get more magnification [4-6].

The SEM analysis can show more and more what in the surveyed area might happen, in comparison with conventional microscopy. Images are sharper and more stereoscopic and some aspects are more noticeable. That is why SEM was used as a complementary analysis method throughout this research $[7 ; 8]$.

\section{Materials and methods}

The experimental material for machining was steel class 16343 according to the CSN 410002 , tempered to 40-44 HRC (34CrNiMo6 according to EN 10269). It is steel with high hardenability, which is designed for highly stressed parts used in engineering. After processing it has a favorable ratio of strength to yield strength and a high toughness, which inhibits crack growth. This material is therefore characterized by high levels of fatigue limit under static and dynamic loads.

For the analysis cutting inserts (plate) were delivered CNMG 120408-M KT-CTP25 (Fig. 1.), CNMG 120408E-M GRADE T9325 (Fig. 2.), and CNMG 432-PM 4325 (Fig. 3.). According to the description these were inserts of cemented carbide and coated. 


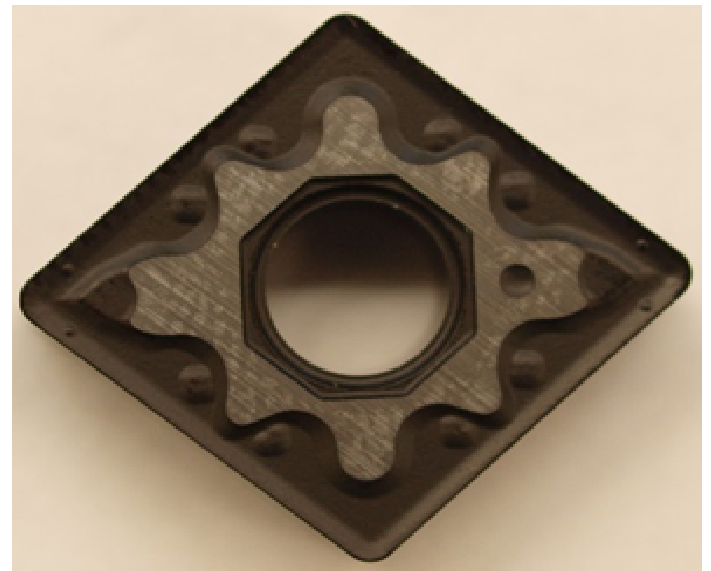

Fig. 1. CNMG 120408-M KT-CTP25

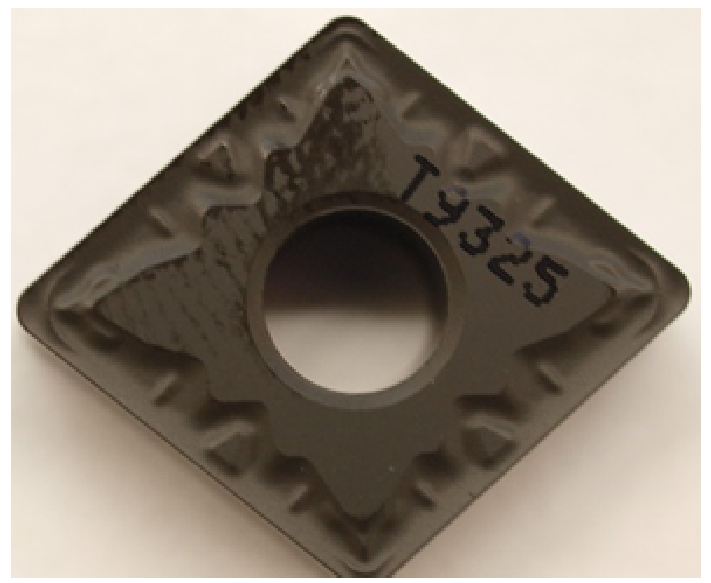

Fig. 2. CNMG 120408E-M GRADE T9325

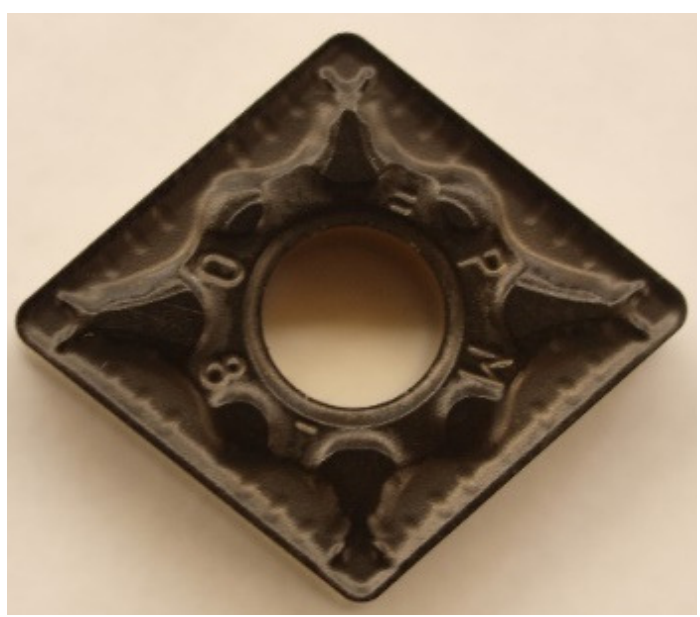

Fig. 3. CNMG 432-PM 4325

The experimental material was turned on the three-axis CNC lathe DOOSAN Lynx 220L with the control system FANUC. The cutting depth was determined as $a_{p}=1.5 \mathrm{~mm}$, because at indicative removal depth of $2 \mathrm{~mm}$ the whole system showed instability. The feed was set as $f=0.3 \mathrm{~mm} \cdot \mathrm{ot}^{-1}$. For all investigated cutting inserts the same tool holder PCLNR $2020 \mathrm{~K} 12$ was used. The experimental cutting speed was determined in the range of $v_{c}=80$ to $120 \mathrm{~m} \cdot \mathrm{min}^{-1}$.

At all replaceable cutting inserts the SEM analysis has been carried out. For evaluation of the inserts the scanning electron microscope Tescan Vega 3 was used (Fig. 4.), which is at FPTM JEPU available $[9 ; 10]$.

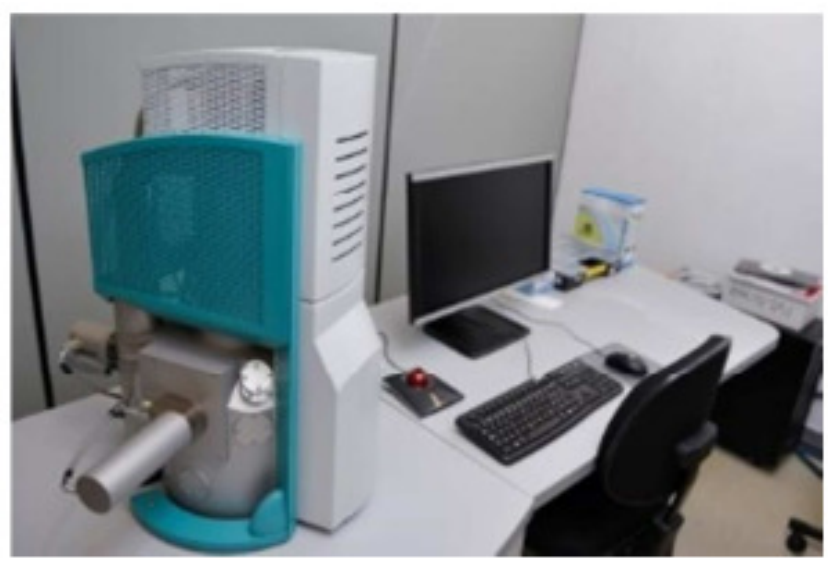

Fig. 4. Scanning electron microscope Tescan Vega 3 


\section{Results and discussion}

Fig. 5 shows the cutting insert CNMG 120408-M KT-CTP25 after machining by $v_{c}=80 \mathrm{~m} \cdot \mathrm{s}^{-1}$. It was possible on the SEM image to observe the typical course wear for the cutting tool. This wear was less intense compared to higher speeds.

For the cutting insert after machining by $v_{c}=100 \mathrm{~m} \cdot \mathrm{s}^{-1}$ (Fig. 6.) it was possible to observe wear where already violation of the tool coating was apparent.

For the cutting insert after machining by $v_{c}=120 \mathrm{~m} \cdot \mathrm{s}^{-1}$ (Fig. 7.) it was possible to observe relatively extensive and intensive wear of the tip and the flank wear. In this figure there are clearly visible individual layers of the coating and the substrate of the cutting insert. It could be a delamination wear, which is for coated inserts relatively common. This insert showed the worst results from all three of the investigated inserts.

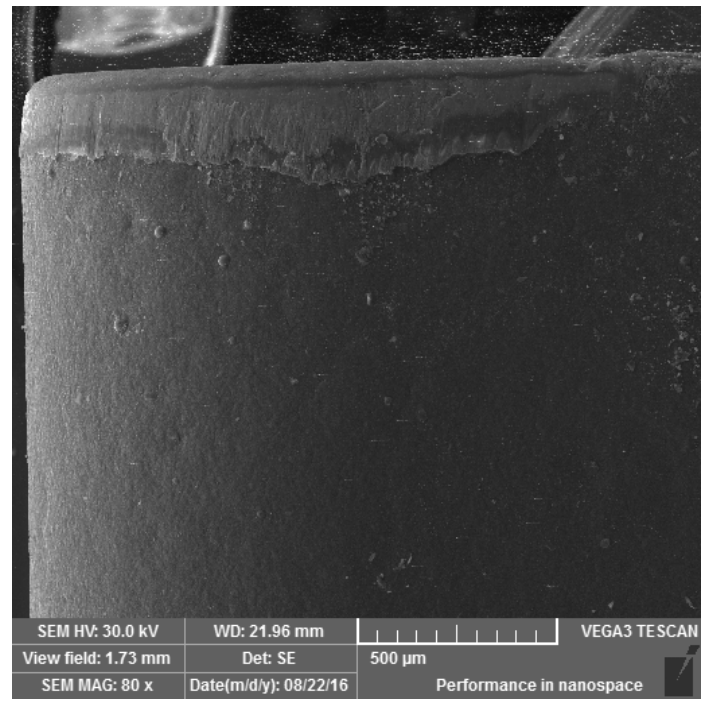

Fig. 5. CNMG 120408-M KT-CTP25, $v_{c}=80 \mathrm{~m} \cdot \mathbf{s}^{-1}$

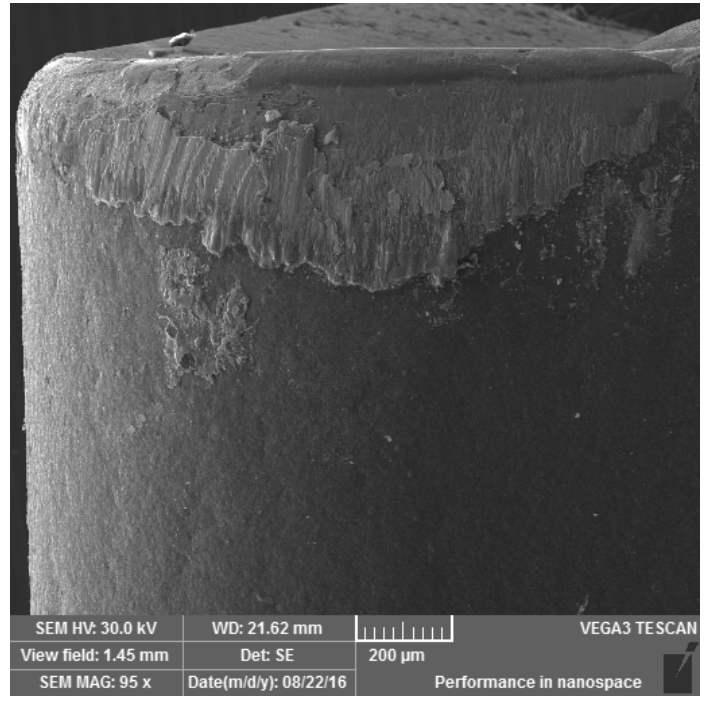

Fig. 6. CNMG 120408-M KT-CTP25, $v_{c}=100 \mathrm{~m} \cdot \mathrm{s}^{-1}$

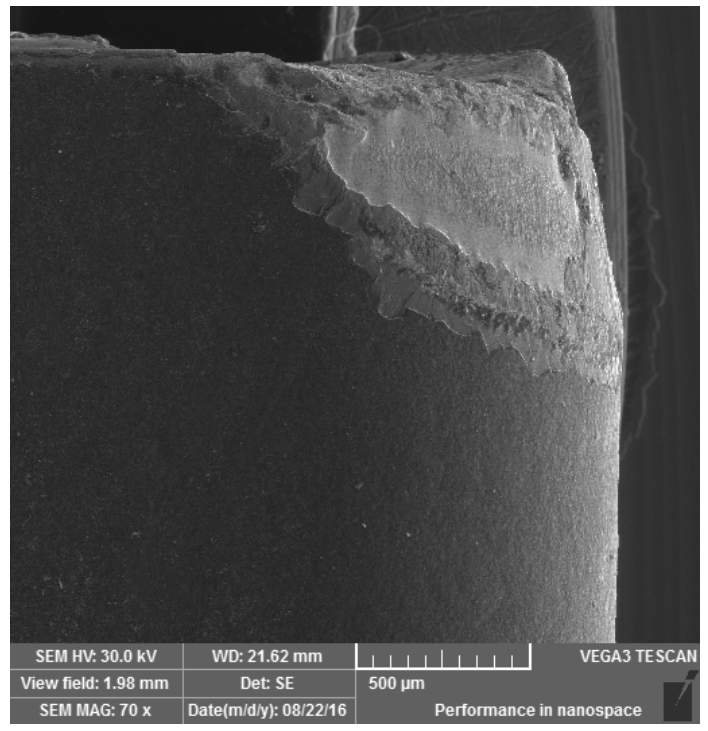

Fig. 7. CNMG 120408-M KT-CTP25, $v_{c}=120 \mathrm{~m} \cdot \mathrm{s}^{-1}$

Fig. 8 shows the cutting insert CNMG 120408E-M GRADE T9325 after machining by $v_{c}=80 \mathrm{~m} \cdot \mathrm{s}^{-1}$. It was possible on the SEM image to observe the typical course wear for the cutting tool, similar to the insert CNMG 120408-M KT-CTP25 $\left(v_{c}=80 \mathrm{~m} \cdot \mathrm{s}^{-1}\right)$. 
Figure 9 shows the cutting insert for $v_{c}=100 \mathrm{~m} \cdot \mathrm{s}^{-1}$ according with the SEM analyses. From this picture it is possible to see similar consequences like for $v_{c}=80 \mathrm{~m} \cdot \mathrm{s}^{-1}$, see Fig. 8 , the wear on the tip of the tool is greater in comparison with the wear for $v_{c}=80 \mathrm{~m} \cdot \mathrm{s}^{-1}$.

The SEM analysis of this insert for $v_{c}=120 \mathrm{~m} \cdot \mathrm{s}^{-1}$ (Fig. 10.) showed that the tool wear of the insert took place uniformly without obvious signs of other damage. The cutting edge is in good condition, there is not visible delamination of coatings in comparison with CNMG 120408-M KT-CTP25.

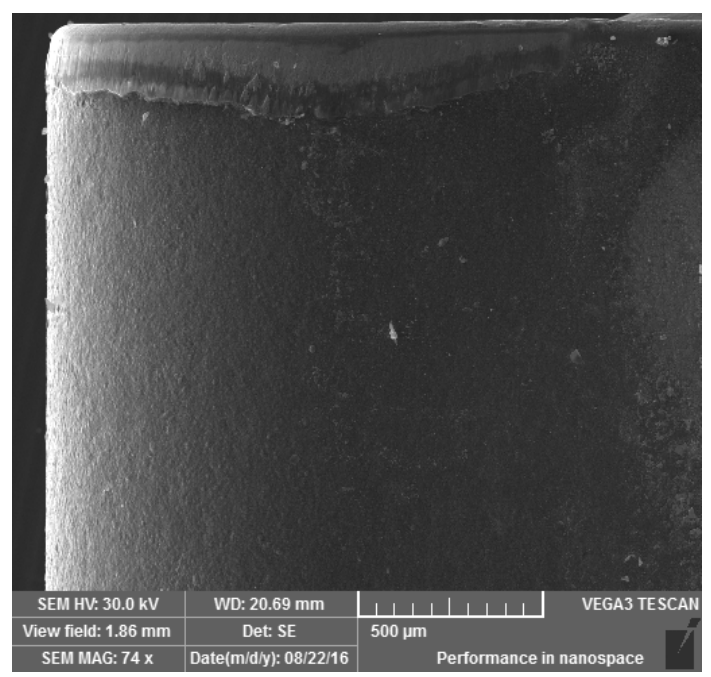

Fig. 8. CNMG 120408E-M GRADE T9325, $v_{c}=80 \mathrm{~m} \cdot \mathrm{s}^{-1}$

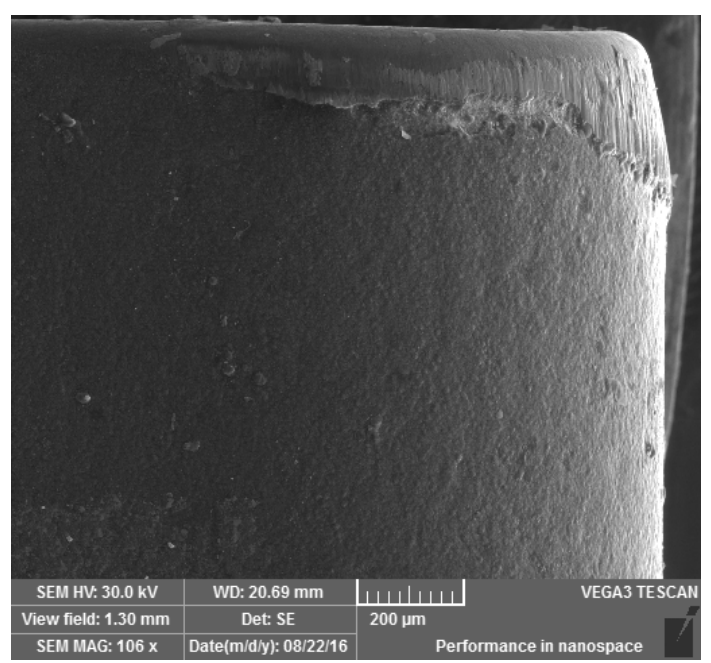

Fig. 9. CNMG 120408E-M GRADE T9325, $v_{c}=100 \mathrm{~m} \cdot \mathrm{s}^{-1}$

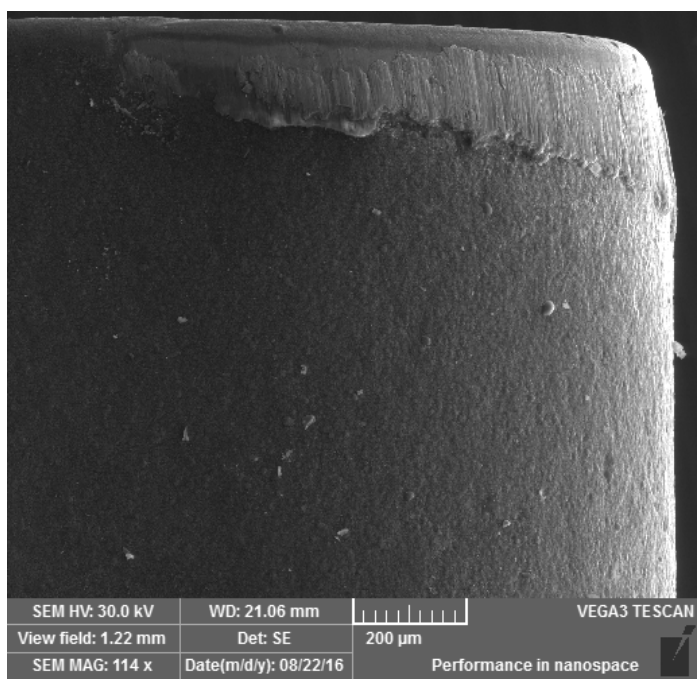

Fig. 10. CNMG 120408E-M GRADE T9325, $v_{c}=120 \mathrm{~m} \cdot \mathrm{s}^{-1}$

For the insert CNMG 432-PM $4325\left(v_{c}=80 \mathrm{~m} \cdot \mathrm{s}^{-1}\right)$ in Fig. 11, there can be observed uniform abrasive wear on the flank and tool tip with the classic course. On the area of the flank is again wear visible similar to what the previous inserts had. This wear by the SEM analysis, compared with the previous, does not reach such a depth and is received only in the second coating, there is no visible penetration in the substrate.

Fig. 12 shows tool wear for $v_{c}=100 \mathrm{~m} \cdot \mathrm{s}^{-1}$. Fig. 13 shows tool wear for $v_{c}=120 \mathrm{~m} \cdot \mathrm{s}^{-1}$. The cutting edge is in good condition, there is not visible delamination of the coatings, like for CNMG 120408EM Grade T9325. 


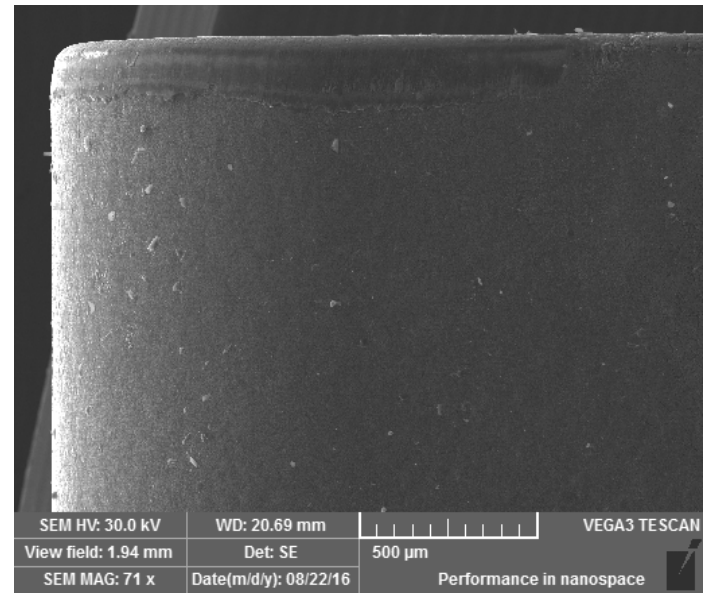

Fig. 11. CNMG 432-PM 4325, $v_{c}=80 \mathrm{~m} \cdot \mathrm{s}^{-1}$

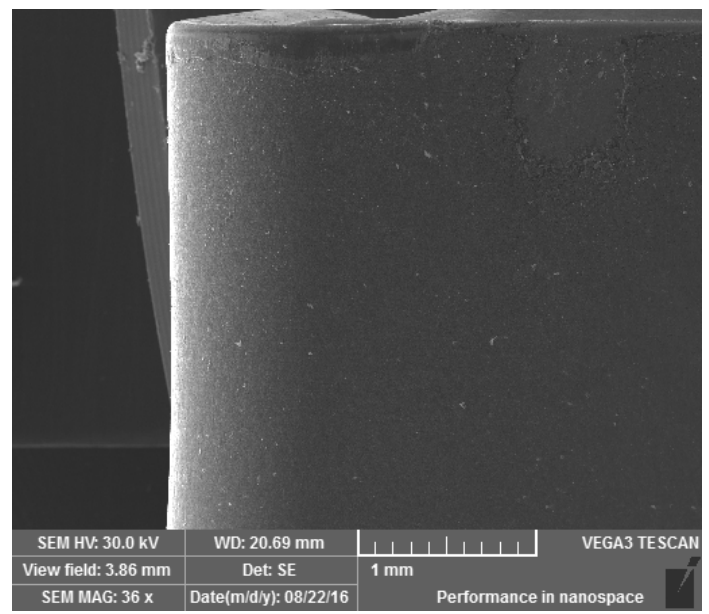

Fig. 12. CNMG 432-PM 4325, $v_{c}=100 \mathrm{~m} \cdot \mathrm{s}^{-1}$

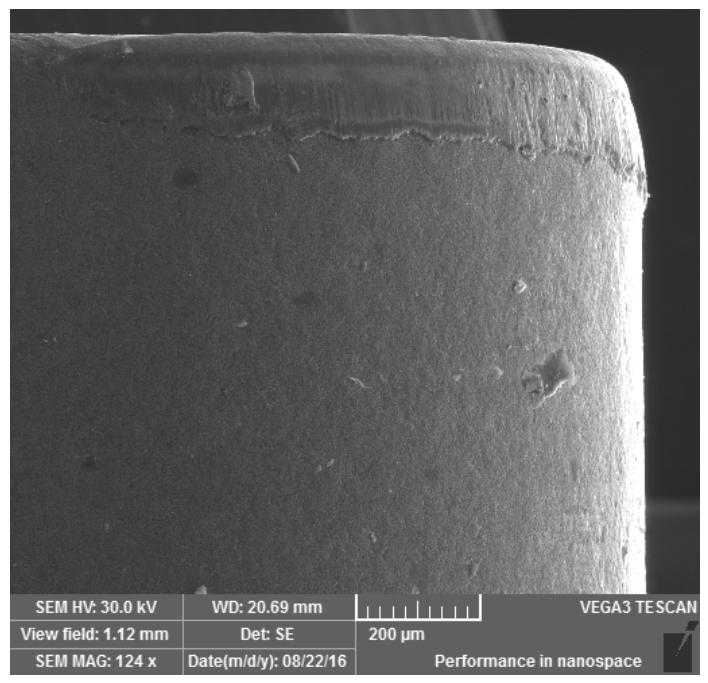

Fig. 13. CNMG 432-PM 4325, $v_{c}=120 \mathrm{~m} \cdot \mathrm{s}^{-1}$

\section{Conclusions}

For the experimental insert CNMG 120408-M KT-CTP25 it was possible to state that according to the SEM analysis the tool wear in the place of the tip has been fairly intense, there are also delaminated layers of the insert coating up to its substrate.

For the experimental insert CNMG 120408E-M GRADE T9325 it was true that the wear according to the SEM analysis was uniform, there was not delamination of the coating layers, neither tearing off of the particles.

For the experimental insert CNMG 432-PM 4325 there could be observed a uniform abrasive wear on the tool flank and tool tip with the classical course. On the area of the flank again wear similar to what the previous inserts had is visible.

For all of the inserts, it was obvious that the greatest abrasive tool wear was for the speed $v_{c}=120 \mathrm{~m} \cdot \mathrm{s}^{-1}$.

According to the SEM analysis of the insert tool wear usually there was relatively uniform abrasion on the flank of the tool. Also, sometimes it occurred in the flank behind the cutting depth "eroded" areas, sometimes large, sometimes small, probably caused by the impacts of chips thrown by the engagement of the tool. Less it occurred at the inserts of the chipping wear of the cutting edge. In a small extent there delaminating wear occurred. Any wear was not yet beyond the tool life of the insert. 


\section{Acknowledgement}

The authors are grateful for the support of grant SGS 2016 UJEP and of grant CZ.1.05/4.1.00/11.0260.

\section{References}

1. Kordik M., Struharnansky J., Martikan A., Stancekova D., Kusmierczak S., Martincek J. Inserts Coating Influence on Residual Stress of Turned Outer Bearings. Manufacturing Technology. Vol. 16, No. 1, 2016 , pp. 132-136.

2. Petru J., Zlamal T., Mrkvica I., Cep R. The Effect of Thermal Shocks on Wear of Exchangeable Sintered Carbide Inserts during the Cutting Process. Manufacturing Technology. Vol. 14, No. 4, 2014, pp. 590-596.

3. Petru J., Schiffner J., Zlamal T., Sadilek M., Stancekova D. Investigations of Cutting Tool Wear While Machining Inconel 718. Manufacturing Technology, Vol 15, No 3, 2015, pp. 396-403.

4. Valasek P. Müller M. Picture Analysis of Failure Areas of Particle Composites. Manufacturing Technology. Vol 14, No 3, 2014, pp. 474-478.

5. Kusmierczak S., Majzner T. Analysis of the causes the degradation of part steam generator by using microscopy methods. Manufacturing Technology. Vol. 16, No. 5, 2016, pp. 995-998.

6. Müller M. Evaluation of single-lap adhesive bond quality by means of electron microscopy methods. Manufacturing Technology. Vol. 16, No. 5, 2016, pp. 1056-1062.

7. Poková M., Cieslar C. Microstructure Evolution of Al-Mn-Si-Fe Alloy Studied by In-situ Transmission Electron Microscopy. In Manufacturing Technology, Vol. 14, No. 3, 2014, pp. 412-417.

8. Cais J. Elektronova mikroskopie. Metalografie. (Electron Microscopy. Metalography). Praha, CZ.1.07/2.3.00/45.00 29, [online][14.05.2016]. Available at:

http://www.csvs.cz/projekty/2014_veda_pro_zivot/data/11_KA3_Jaromir_Cais_2_Elektronova_ \%20mikroskopie_a_\%20EDS_\%20analyza_metodicka_prirucka.pdf. ISBN 978-80-86302-67-6. (In Czech).

9. Czajkowska A., Kossakowski P., Wcislik W., Stasiak-Betlejewska, R. Application of Electron Scanning Microscope in the Analysis of the Structure of Casting Non Conformities Aimed at Optimization of Technological Process Parameters. Manufacturing Technology. Vol. 13, No. 2, 2013, pp. 164-169.

10. Svobodova J. SEM and EDS Analysis Used in Evaluation of Chemical Pre-treatment Based on Nanotechnology. Manufacturing Technology. Vol.14, No.3, 2014, pp. 461-467. 